\title{
Genetic Factors Consequence on Productive and Reproductive Recital Traits of Kajli Sheep at Two Ecologies in Pakistan
}

Farmanullah $^{1,8^{*}}$, Khalid Javed ${ }^{2}$, Mohammad Salim ${ }^{3}$, Momen Khan ${ }^{4}$, Sajid Ali ${ }^{5}$, Muhammad Altaf Hussain ${ }^{1}$, Sajjad Ahmad $^{1}$, Suliman Khan ${ }^{1}$, Ihsanullah Kakar ${ }^{1}$, Mehmood ul Hassan ${ }^{1}$, Khalid Khan ${ }^{6}$, Sakandar Khan ${ }^{7}$

${ }^{1}$ Faculty of Veterinary and Animal Sciences, Lasbela University of Agriculture, Water and Marine Sciences, Uthal, Balochistan, Pakistan

${ }^{2}$ Faculty of Animal Production and Technology, the University of Veterinary and Animal Sciences, Lahore, Punjab, Pakistan

${ }^{3}$ Departments of Forestry and Wildlife Management, University of Haripur, Khyber Pakhtunkhwa, Pakistan

${ }^{4}$ Livestock and Dairy Development Department, Khyber Pakhtunkhwa, Pakistan

${ }^{5}$ Agricultural university Peshawar Amir Muhammad Khan campus Mardan

${ }^{6}$ Department of Economics,Lasbela University of Agriculture, Water and Marine Sciences, Uthal, Balochistan, Pakistan

${ }^{7}$ Department of Parasitology University of Veterinary and Animal Sciences Lahore, Pakistan

${ }^{8}$ Key Laboratory of Agricultural Animal Genetics, Breeding and Reproduction, Education Ministry of China, College of Animal Science and Technology, Huazhong Agricultural University, Wuhan 430070, People's Republic of China

The present investigation was to exhibit hereditary attributes of Kajli sheep regarding development execution in the setting of hereditary parameters. Reproduction execution record information was gathered of 13715, Kajli Sheep for the term of 1994-2010 from two homesteads and investigated. The characteristics of fixation were weight during childbirth, weight at weaning, year weight, everyday weight gain at pre-weaning, and weight of greasyfleece wool, the evaluated heritability, for example, $0.05 \pm 0.019,0.069 \pm 0.016,0.015 \pm 0.020,0.056 \pm 0.016$, and $0.170 \pm 0.60$, separately in Kajli Sheep. The benefits of rearing estimation of sire and dam of two ranches with respect to hereditary attributes indicated huge variety. It is presumed that quality recurrence and heritability evaluations can contrast among populaces and the job of ecological conditions to which the herds were uncovered and low encouraging arrangement may likewise be in charge of low heritability for different execution characteristics. The herd may be offered advantageous apportion routinely which credit for these distinctions. It is additionally clear that enhancements in the efficiency of Kajli sheep might be accomplished through better bolstering and improved oversee managemental practices.

Keywords: Sheep, breeding values, performance, Heritability, traits.

Copyright @ 2020: This is an open-access article distributed under the terms of the Creative Commons Attribution license which permits unrestricted use, distribution, and reproduction in any medium for non-commercial use (NonCommercial, or CC-BY-NC) provided the original author and source are credited.

\section{INTRODUCTION}

Small ruminants in rangeland assume an essential job in the change of roughages and rummage to monetarily worth [1] reported that the transformation of scavenges, roughages in the biggest range land to attractive esteem and farming side-effects, such as financially important items including meat, milk and wool have been demonstrated by small ruminants themselves. It is for the most part seen that in a nation normal populace is worried about domesticated animals. While the most fundamental and assume a key job in animals ranchers more than a huge number of vocation are sheep and goats. It is considered as a noteworthy wellspring of domesticated animals ranchers vocation, and national hereditary asset of a nation. Small ruminants are additionally concerned and assume basic job with the parched locals and scopes of a nation where dairy cultivating and crop rehearses are restricted to holding a little land. Small ruminants in spite of the fact that isa significant wellspring of creature generation in creating nations, appear to have little consideration from veterinary consideration and generation improvement. They are the fundamental supply of meat, fleece and are utilized in formal celebrations all through the nation, giving significant exchange. Profoundly flexibility of sheep and goat to change for each sort of climatic condition is normal. For the most part, the country territories money related framework and financial condition are legitimately corresponding to the small ruminants raising. Financially, small ruminants are the primary wellspring of ranchers in provincial zones just as in the unforgiving condition worried about the emergency of harvest disappointment because of regular downpour disappointment occasion. In this manner, the farmland 
poor ranchers communicated sheep as a "fund lift" [2]. Rearing in sheep is a significant undertaking worldwide to secure creature generation yielding sustenance, the most significant sustenance for individuals' sustenance is milk and meat [3]. The hereditary and condition them two are significant and assume a key job in the improvement creature execution of an individual, absence of this central point which incorporates, for example, rearing designs for choice, great administration, high nutritious feed, and essential illness control program [4].

The gainful and regenerative characteristics are affected by condition just as genotype. The presentation of an individual is affected by hereditary and condition, while the level of an individual improvement for hereditary is, for the most part, be liable to the variety of hereditarily inside an attribute and their relationship with different qualities. The productive techniques for determination, and reproducing plans planning need to comprehend the fundamental information which is basic for development, for example, repeatability, heritability, and the relationship of different characteristic with one another. The hereditary wellsprings of variety incorporate all distinctions that might be ascribed because of heredity. Determination is a significant apparatus for revising the craving characteristics under examination to improve the group normally. Reproducing plans to make effective and watched the choice reaction, the heritability idea is increasingly profitable for productive rearing projects. In rearing system, the heritability estimations of high measure demonstrate the added substance quality activity have a key job for development the attributes under thought. Subsequently, to accomplish progressively attractive posterity from the crowd populace it will be essential to take into account mating the best creatures in the group populace. While the non-added substance quality activity, for example, predominance, epistasis, and over strength might be basic when a characteristic has low heritability. To make beneficial determination process and gainful, the hereditary components and parameters of these characteristics which are significant and assume the key job, ought to be evaluated precisely. The worthwhile determination procedures and program plan in little ruminants' essential hereditary parameters and significant characteristics to evaluate were weight during childbirth, day by day weight gain at preweaning, weight at weaning, and yearling weight. The phenotype and execution of another conceived is the aftereffect of dam and sire genotype, where the maternal and directly added substance quality are in charge of the development of the youthful[5]. The hereditary improvement is deduced a change to improve the stock overall or the advantages to the proprietor network or benefits for people, it will make adjustment in an emphatically heading to all. Besides this, the heading of positive improvement will acquire change and the benefit present moment or long term, the impact of the change will be the purpose behind the advantages. These change, impact and improvement together willbe considered a positive stage an entire no kind of damage will make to broaden. It must be remembered when to begin a program of reproducing plan to improve hereditary upgrade in a populace worried about social, condition, society, monetary, and network setting were to work the rearing plans. The improvement in quality will be conceivable and best accomplished, if the national domesticated animals rearing plans totally have as indispensable impact for the animals improvement, they will build up the expansive formative target for the different condition based on creation (genetic improvement methods to support sustainable utilization; the state of the world animal genetic resources for food and agriculture). The point of any rearing customized is to hereditarily improve one additional quality of financial significance in a populace. The decision of any reproducing and choice framework relies upon the level of the legacy of the characteristic, the determination weight (choice differential) and the age interim. The fundamental requirements to guarantee hereditary advancement are the usage of an exhibition recording plan and of sound assessment methodology and the association of a customized for the spread (dissemination) of improved hereditary material in the populace. Creature rearing means to improve hereditarily milk and meat generation through determination and crossbreeding, the generation of improved kinds appropriate for ecological conditions they are called to perform in and the assessment of the significant natural impacts influencing creature profitability. The presentation of thoroughbreds and crossbreds under a semi-serious generation framework, the methods pursued the assessment of unrivalled people and the choice frameworks. The decent variety of targets, the diverse administration frameworks and breeds, the dimension of rancher's association and the level of inclusion of government foundations being developed, usage and upkeep of account plans, are a portion of the purposes behind the various projects towards the hereditary improvement of sheep and goats(Breeding systems and selection strategiesfor sheep improvement in Cyprus, book). In this way, the contemporaneous key has been producing for examination of different execution qualities of the financial significance of this breed. The presentation of an individual is identified with the condition also hereditary make-up. Which can influence the presence of the elements and these hereditary parameters indicated variety because of estimation technique, degree of informational collection, area, district, informational index, timespan, and populace measure. The characteristics of financial significance in sheep included, for example, weight during childbirth, weight at weaning, weight at year astute, day by day weight gain at pre-weaning, and weight of greace fleece wool. Hereditary change in the presentation of Kajli sheep has been hard to screen on the grounds that there has been little utilization of factual procedures to isolate hereditary from year to year ecological variety. A few 
components may add to change in execution with time. Many arranged changes on a property, for example, field advancement and improved cultivation rehearses are intended to expand current rush efficiency, while land debasement, declining soil ripeness or a cycle of draft years can prompt a descending pattern in both the quality and amount of generation. The failure to recognize hereditary improvement amidst year to year variety has been disappointing. Numerous raisers have put their confidence in choice practices which have been approved in research runs, where hereditary addition can be estimated against a control, or in sheep classers with a collection of industry experience.

\section{MATERIALS AND METHODS}

The exhibition information records of, 13715 lambings created by 3342 ewes sired by 128 rams in Kajli sheep from 1994 to 2010 were utilized in the present analysis. The information of pure breed, and show during 1994-2010 of Kajli sheep balanced at Farm $\mathrm{A}$ and Farm B were used in the present investigation. The normal day by day ranch creature encouraging practices of touching was kept up, for example, to go detached for brushing the ewes and sheep in documented at morning and come back to the outbuildings at night everyday homestead rehearses. The rearing stock was likewise present, which was incorporated of 20 ewes and one ram for reproducing objective. Green regular grain was additionally offered to the creatures when coming back from field subsequent to munching if accessible, and the pregnant creatures were kept in uncommon consideration and bolstering the board, as offered $1 \mathrm{Kg}$ move blend in the most recent month of pregnancy. Further, they likewise practice and remember the reproducing goal to offer the ewes two weeks before rearing season the flushing stipend. Practically both the managemental and encouraging practices in the ranch were the equivalent, then again the climatic conditions and condition was wild and work which may cause the variety. The reproducing ewes have been chosen from and among the ranch created female stock essentially based on compliance and breed qualities and some weight was likewise given to development attributes, body size and fleece production. The determination of the males was, in any case, at first dependent on family data. For the most part, the ewes were reared once every year in harvest time season and sheep got during the spring season. Nonetheless, in certain years two times every year reproducing of the ewes was polished yet later on it was stopped to oversee managemental reasons. The ewes which were not reproduced during harvest time season were mated in the resulting spring season to sheep during the fall season. The creatures were uncovered two times per year i.e., spring and fall. The Rams utilized in rearing were for the most part ranch delivered yet outside acquaintance had additionally been finished with give hereditary heterogeneity. Ordinarily, 10-15 rams for every season were chosen and utilized for rearing. Significant push in by and large rearing arrangement had been the improvement of meat creation and a little consideration had been paid to fleece attributes. It was seen in practices to keep the creatures during the time in open fenced in areas. The grown-up creatures were kept in open stable with satisfactorily secured zone to give shade and safe house during the unforgiving climate. It was watched for touching that all creatures conveyed from 8:00AM to 5:00PM, in the late spring, and spring season however in the winter season with little change in the brushing plan from 9:00 am to 4:30 pm. The encouraging of the creatures were for the most part through brushing of accessible occasional feed and scavenges yet thinks were enhanced during shortage period and in breeding seasons for flushing. It was seen that during the time feed arrangement fluctuated by the accessibility of grain crops. Consistently, the bolstering framework and practices kept up always with the exception of a couple of changes, as and when required. For the most part the creatures were shorn two times per year i.e., in spring and harvest time seasons. The sheep conceived in spring were first shorn in harvest time season and the other way around. From that point, the shearing of every creature was done after like clockwork. Diverse wellspring of hereditary variety in these attributes needs to investigate different execution information of these characteristics through the appropriate factual system to discover the level of variety in hereditary sources. The exact information investigation required legitimate expulsion of anomaly and release before beginning information examination. The measurable investigation needs just total and typical records. The spreadsheet of MS Excel for information passage and investigation were utilized for the entire information. The Restricted Maximum Likelihood technique [6], fitting an Animal Model were utilized for assessing the hereditary parameters viz. heritability. The majority of the accessible family data was incorporated into the investigation trying to limit the inclination because of determination and non-arbitrary mating. The combination foundation (variance of function values-2 $\log$ likelihood) for different hereditary parameters was $1 \times 10^{-8}$

\section{Heritability Estimation}

The model of heritability estimation mathematically was assumed as follow

Yijk $=\mu+\mathrm{Fi}+\mathrm{Aj}+$ eijk Model-2

Where,

$\mathrm{Y}$ ijk = estimation of a specific quality

$\mu=$ populace mean

$\mathrm{Fi}$ = fixed effects observed to be significant from the initial analysis

$\mathrm{Aj}=$ random additive effect of $\mathrm{j}^{\text {th }}$ animal with mean, Zero and fluctuation $\sigma^{2} \mathrm{~A}$

Eijk $=$ random error with mean zero and variance $\sigma^{2} \mathrm{e}$ The heritability was determined by the accompanying equation Heritability $(\mathrm{h} 2)=\sigma 2 \mathrm{~A} / \sigma 2 \mathrm{P}$ 
For the reason, the bivariate investigation was completed utilizing a singular creature model REML method [6]. The fixed impacts for different execution qualities in this investigation were same as considered in the univariate examination (Model 2).

Heritability $\left(\mathrm{h}^{2} \mathrm{i}\right) \quad=\sigma^{2} \mathrm{Ai} / \sigma^{2} \mathrm{pi}$

Phenotypic connection $(r P)=$ Cov pi. $p \mathrm{j} / \sigma$ pi. $\sigma \mathrm{pj}$

Hereditary connection $(\mathrm{rG})=\operatorname{Cov} \mathrm{Ai} . \mathrm{Aj} / \sigma \mathrm{Ai} . \sigma \mathrm{Aj}$

Environmental correlation $(\mathrm{rE})=\mathrm{Cov} \mathrm{E}$ i. $\mathrm{Ej} / \sigma \mathrm{Ei} . \sigma \mathrm{Ej}$

Where,

$\mathrm{h}_{\mathrm{i}}^{2}=$ heritability of $\mathrm{i}^{\text {th }}$ trait

$\sigma^{2} \mathrm{Ai}=$ additive genetic variance for $\mathrm{i}^{\text {th }}$ trait

$\sigma_{\mathrm{pi}}^{2}=$ phenotypic variance for $\mathrm{i}^{\text {th }}$ trait

$\sigma_{\mathrm{Ei}}^{2}=$ residual variance for the $\mathrm{i}^{\text {th }}$ trait

$\operatorname{Cov}_{\text {pi. pj }}=$ phenotypic covariance for the traits $\mathrm{i}$ and $\mathrm{j}$

$\operatorname{Cov}_{\text {Ai. }}$ Aj $=$ additive genetic covariance for the traits $\mathrm{i}$ and $\mathrm{j}$

$\operatorname{Cov}_{\mathrm{Ei} . \mathrm{Ej}}=$ residual covariance for the traits $\mathrm{i}$ and $\mathrm{j}$

Every one of these investigations was performed utilizing Derivative Free Restricted Maximum Likelihood (DFREML) set of PC programs (Meyer, 2000). The standard errors of heritability assessments acquired from the univariate examination were utilized for this reason.

\section{Breeding Values Estimation, And Genetic Trends}

The best linear unbiased predication (BLUP) [7] technique was utilized in creatures for the estimation, rearing estimations of various execution attributes. The PC program set, for example, DFREML, likewise creating, as a result, the assessed rearing qualities. As an outcome the assessed rearing qualities were fitted in a model of fixed impact, for example, year of birth having just the fixed impact. To outline appropriately hereditary pattern, the rearing qualities least squares arrangement against the year of birth were drawn. The assurance of various phenotypic characteristics pattern were plotted the estimations of different phenotypic execution attributes against the time of birth. The year or period of birth ordinarily impacts the presentation of creatures because of varieties in managemental, bolstering, natural conditions just as choice of creatures. In small ruminants, the heritability is utilized as the most usual parameter. All in all, in the populace centre around the individual execution which is influenced by relative condition and heredity, this is consider all in all for concentrate the hereditary piece of that populace.

\section{RESULTS \\ Heritability Estimates}

Data wasanalyzed for the estimation of heritability of birth weight, weaning weight, yearling weight, greasy fleece weight and normal day by day weight gains. The evaluations acquired are abridged in Table 1 . The heritability of birth weight evaluated was acquired as $0.054 \pm 0.019$. The birth weight estimate depended on birth records of 13715 sheep delivered by 3342 ewes sired by 128 rams. The heritability estimate for weaning weight in the examination was $0.069 \pm$ 0.016 and depended on 9331 weaning records of sheep delivered by 3342 ewes sired by 128 rams. The yearling weight heritability estimation was $0.015 \pm 0.020$. The heritability of yearling weight assessed of 6121, information records of animals based, with 2349 of descendants records, and dam sired by 105 rams. The heritability estimate for pre weaning normal day by day addition was $0.056 \pm 0.016$. The absolute estimation animals based were 9331, 128, and 3342, Sired, rams and ewes separately. The heritability estimate for the weight of wool was $0.17 \pm 0.060$. The estimation animals based were 9030, 117, and 1968, sired, rams, and ewes separately.

Table-1: Heritability estimates of different performance traits

\begin{tabular}{|l|l|l|l|}
\hline Traits & No. of sire record & No. of dam record & Heritability \\
\hline Birth Weight & 128 & 3342 & $0.054 \pm 0.019$ \\
\hline Weaning weight & 128 & 3342 & $0.069 \pm 0.016$ \\
\hline Yearling weight & 105 & 2349 & $0.015 \pm 0.020$ \\
\hline Pre-weaning daily gain & 128 & 3342 & $0.056 \pm 0.016$ \\
\hline Greasy fleece weight & 117 & 1968 & $0.170 \pm 0.060$ \\
\hline
\end{tabular}

\section{Estimation of Breeding Values}

Estimated breeding values (EBVs) for birth weight, weaning weight, yearling weight, wool weight, and pre-weaning normally everyday gain, are displayed in Table 2. The evaluated breeding values for homestead A were, for the birth weight from - 0.205 to $0.164 \mathrm{kgs}$ in males. The comparing esteems were from 0.149 to $0.180 \mathrm{kgs}$ in females. The evaluated breeding an incentive for weaning weight went from - 1.029 to $1.822 \mathrm{kgs}$ in males and relating qualities were from 1.205 to $1.555 \mathrm{kgs}$ in females. The breeding quality assessed for yearling weight was -0.152 to 0.285 in males and -0.159 to 0.224 in females. The assessed reproducing an incentive for pre-weaning development rate was -0.194 to $0.212 \mathrm{gms}$ in males and -0.174 to $2.00 \mathrm{gms}$ in females, and for wool weight it was - 0.247 to $0.708 \mathrm{kgs}$ and -0.429 to $0.575 \mathrm{kgs}$ in males and females individually. The evaluated reproducing values for homestead B were, for the birth weight from - 0.157 to $0.173 \mathrm{kgs}$ in males. The relating esteems were from 0.148 to $0.145 \mathrm{kgs}$ in females. The evaluated rearing an incentive for weaning weight rangefrom - 1.478 to $0.284 \mathrm{kgs}$ in males and relating qualities were from 0.976 to $1.923 \mathrm{kgs}$ in females. The rearing worth 
evaluated for yearling weight range from - 0.198 to $0.176 \mathrm{~kg}$ in males and -0.166 to $0.170 \mathrm{~kg}$ in females. The evaluated reproducing an incentive for pre-weaning development rate was -0.281 to 0.195 gms in males and
- 0.205 to 0.148 gms in females, and for wool weight it was -0.380 to $0.706 \mathrm{kgs}$ and -0.267 to $0.590 \mathrm{kgs}$ in males and females individually.

Table-2: Estimated breeding values for males and females

\begin{tabular}{|l|l|l|l|l|}
\hline Traits & No & EBVs for males & No EBVs for females \\
\hline Farm A & 2984 & -0.205 to 0.164 & 6771 & -0.149 to 0.180 \\
\hline Birth weight & 2984 & -1.029 to 1.822 & 6771 & -1.205 to 1.555 \\
\hline Weaning weight & 1443 & -0.152 to 0.285 & 5230 & -0.159 to 0.224 \\
\hline Yearling weight & 2984 & -0.194 to 0.212 & 6771 & -0.174 to 0.200 \\
\hline Pre weaning daily gain & 220 & -0.247 to 708 & 3926 & -0.429 to 0.575 \\
\hline Greasy fleece weight & 22.5 \\
\hline Farm B & 176 & -0.157 to 0.173 & 624 & -0.148 to 0.145 \\
\hline Birth weight & 176 & -1.478 to 0.284 & 624 & -0.976 to 1.923 \\
\hline Weaning weight & 94 & -0.198 to 0.176 & 429 & -0.166 to 0.170 \\
\hline Yearling weight & 176 & -0.281 to 0.195 & 624 & -0.205 to 0.148 \\
\hline Pre weaning daily gain & 27 & -0.380 to 0.706 & 285 & -0.267 to 0.590 \\
\hline Greasy fleece weight & 270.
\end{tabular}

The evaluated reproducing values for sire in ranch $\mathrm{A}$ and ranch $\mathrm{B}$ are given in Table 3. In homestead A; for birth weight, weaning weight, yearling weight, pre weaning every day put on and wool weight, it went from -0.169 to $0.164 \mathrm{kgs},-1.029$ to $1.694 \mathrm{kgs},-0.151$ to $0.285 \mathrm{kgs},-0.190$ to $0.212 \mathrm{gms}$, and -0.146 to 0.520 kgs, individually. In homestead B; for birth weight, weaning weight, yearling weight, pre weaning day by day put on and wool weight, it went from - 0.157 to $0.173 \mathrm{kgs},-1.478$ to $2.846 \mathrm{kgs},-0.198$ to $0.176 \mathrm{kgs}$, 0.281 to 0.195 gms and -0.335 to $0.706 \mathrm{kgs}$ separately.

Table-3: Estimated breeding values for Sire

\begin{tabular}{|l|l|l|l|l|}
\hline Particulars & Farm A & Farm B \\
\hline Traits & Sire No & EBVs & Sire No & EBVs \\
\hline Birth weight & 105 & -0.169 to 0.164 & 18 & -0.157 to 0.173 \\
\hline Weaning weight & 105 & -1.029 to 1.694 & 18 & -1.478 to 2.846 \\
\hline Yearling weight & 78 & -0.151 to 0.285 & 14 & -0.198 to 0.176 \\
\hline Pre weaning daily gain & 105 & -0.190 to 0.212 & 18 & -0.281 to 0.195 \\
\hline Greasy fleece weight & 63 & -0.146 to 0.520 & 11 & -0.335 to 0.706 \\
\hline
\end{tabular}

EBVs: estimated breeding values

\section{DISCUSSION \\ Birth weight}

The estimate of heritability for birth weight in the present investigation was $0.054 \pm 0.019$ which was low and it was in concurrence with numerous researchers $[8,9,10,11,12$. Analyzed information data on lambing records of 1285 Lohi ewes kept at Livestock Production Research Institute Bahadurnagar for the time of 1960-90 and reported heritability estimate of birth weight as $0.10 \pm 0.02$ which was in concurrence with the present examination[8]. Analyzed execution information on Hissardale sheep kept up at Livestock Experiment Station Jahangirabad and revealed the heritability estimate for body weight during childbirth as $0.08 \pm 0.02[12]$. Numerous specialists revealed heritability estimates higher than the present investigation[13-17]. analyzed information data on 16,470 lambings of 5311 Kajli ewes kept at Livestock Experiment Station Khushab and Khizarabad and detailed heritability estimate of birth weight as $0.14 \pm 0.05$ [18]. Analyzed information on Rambouillet sheep kept at Livestock Experiment Station Jaba distt
Mansehra (KP) Pakistan and detailed heritability estimate as $0.07 \pm 0.02$ which was near the heritability gotten in the present investigation $(0.054 \pm 0.019)$. The sheep farming were rehearsed, breed, informational collection, climatic conditions, biological zones, creation framework, size of the information, and technique for estimation may cause for the investigation among different research reports. To diminish the mortality during childbirth the mass determination hasa vital job as to improve higher birth weight and minimized early mortality in sheep on account of the event wide change in birth weight.

\section{Weaning Weight}

Heritability estimate of weaning weight for the present investigation was $0.069 \pm 0.016$ and it was in concurrence with discoveries of different reseachers [10,19], Akhtar et al. [10, 12].(10) Data assessed of Rambouillet Sheep kept up at Livestock Experiment Station Jaba District Mansehra (KP)[10], Pakistan and detailed heritability for weaning weight as $0.04 \pm 0.11$ and it was not exactly the present investigation. Studied 
information on different sheep and ewe qualities and detailed heritability evaluates as 0.09 for weaning weight which was in a little close concurrence with the gauge got in the present examination. Numerous different specialists reported a lot higher for different breeds the weaning weight heritability estimation of sheep in various nations and areas [21, 18, 11, 15, 17]. These specialists announced heritability assessments going from 0.13 to 0.33 [21] in Kajli in Pakistan and Masi sheep in Western Australia, individually. These appraisals were not in accordance with the outcomes got in the present investigation. The consolidated impact as ecological and hereditary have an essential job in an individual execution. Along these lines, the variety and qualification in the prior examinations and the present diverse sheep breed might be because of these impacts[22].

\section{Yearling weight}

The heritability estimation for yearling weight in kaji sheep as acquired in the present examination was $0.015 \pm 0.020$ [13] detailed heritability gauge for yearling weight as $0.08 \pm 0.05$ by fatherly half-sib investigation in Kajli sheep of Pakistan. These outcomes are not close concurrence with the consequences of the present examination. A few scientist data revealed higher heritability gauges for yearling weight $[21,11,18,21]$ evaluated hereditary parameters of Merino sheep kept up in Western Australia and detailed heritability estimate for yearling weight going from $0.27-0.44$ crosswise over model and genders[11]. Likewise revealed to some degree higher gauge of heritability $(14 \pm 0.08)$ for the characteristic in Kermani sheep kept up at Shahrbabak Sheep Breeding Research Station in Iran during the period 1993-1998. $\mathrm{Be}$ that as it may, Borg revealed a lot higher gauge (0.35) of heritability for yearling weight which was likewise not in concurrence with the heritability gauge of the present examination. [12] detailed somewhat higher gauge of heritability for yearling weight $(0.15 \pm 0.04)$ in Hissardale sheep. The contrasts between the heritability gauges as got in the present examination and detailed in writing might be because of contrasts in breeds, areas, timespans, size of informational collection or technique for estimation alongside other managemental rehearses.

\section{Pre-weaning normal day by day weight gain}

The heritability estimate for pre weaning normal day by day weight gain in Kajli sheep as got in the present investigation was $0.056 \pm 0.016$ [23] result revealed heritability gauge for pre weaning normal everyday weight gain as 0.037 by fitting creature model in Scottish Black Face breed. This outcome was in fairly close concurrence with the present investigation. A few specialists reported higher heritability gauges for this attribute[8,14,24,25,26,18]. [8] analyzed information data by fatherly half-sib analysis in Lohi sheep and observed heritability as $0.22 \pm 0.04$. [12] investigate heritability for pre weaning normal day by day gain as $0.11 \pm 0.03$ in Hissardale sheep. The present investigation indicated logical inconsistencies and refinement among others considers in discovering, it might be because of where sheep cultivating was rehearsed, contrasts of breed, environmental and climatic variety.

\section{Greasy fleece wool weight}

The heritability gauge of the fleece wool as acquired in the present analysis was $0.170 \pm 0.060$. A few specialists detailed higher heritability gauges for this attribute than those of the present investigation[21,19,16,14,24,18]. Analyzed information data to gauge hereditary and phenotypic parameters from a Western Australian exploratory herd of Merino sheep and revealed heritability estimation of wool weight extending $0.30-0.42$ crosswise over model and genders [15] reported the heritability gauge of fleece as 0.54 by utilizing REML with animal model for Targhee sheep. The contrasts between the heritability assesses as acquired in the present analysis and reported in writing might be because of contrasts in breeds, areas, timeframes, size of informational collection or strategy for estimation alongside other managemental rehearses. The low gauge of heritability for gainful characteristic demonstrated that the attributes were presumably not affected by added substance quality activity and that the variety because of natural components was increasingly significant. This required the utilization of an extraordinary strategy for determination and mating for the improvement of the crowd. Better chronicle and improvement through bolstering and the executives are the most fitting potential outcomes. The heritability appraisals of practically every one of the characteristics under study were low. The heritability evaluations fluctuated between breeds, herds, the dimension of profitability, strategy for estimation and even timeframes for a specific quality. Inbreeding [27] might lessen the hereditary fluctuation, while, diverse administration and natural factors in various breeds, crowds and years may build the phenotypic variety. The low gauge of heritability could likewise be an element of lower creation [28], misidentification [29] and for animal model; fragmented families may likewise have added to be lower heritability. The low heritability is caused by a low hereditary fluctuation as well as rather by a higher phenotypic change because of the little size of the group and arbitrary and unidentified ecological elements[30]. Considering, that the atmosphere, sickness and other ecological components apply more noteworthy consequences for execution in sub-tropical and tropical area than mild areas, it was not amazing that heritability might be low.

\section{Estimation of breeding values}

The hereditary patterns for birth weight in Kajli sheep indicated a diminishing pattern and the phenotypic pattern was fluctuating, though, the hereditary and phenotypic pattern for weaning weight demonstrated fluctuating pattern. For yearling weight, 
hereditary and phenotypic pattern was additionally seen which show change, pre-weaning development rate likewise not measurement. The phenotypic pattern for wool yield indicated a small expanding pattern. The general pattern was static and this was comparable with the outcomes exhibited by [24] who observed that rearing an incentive for rams went from - 0.447 to 0.216 for birth weight; - 1.512 to 2.859 for weaning weight, 1.686 to 2.089 for yearling weight; - 0.0144 to 0.0255 for pre-weaning gain and - 0.0045 to 0.0062 for post weaning gain. The general hereditary pattern was static. The assessed reproducing estimations of the populace among for the least squares means were demonstrated wide change. Though, finding of [30,31] and did not coordinate with the present investigation[31]. Directed aconsideration to assess the reaction of Menz sheep to choice for yearling live weight (WT12) and fleece wool weight (GFW) joined in a financial list. They announced the aftereffects of this reproducing system got somewhere in the range of 1998 and 2003. Normal yearly hereditary determination reactions for WT12 and GFW were 1.506 and $0.043 \mathrm{~kg}$ in the chose group and 0.392 and $-0.008 \mathrm{~kg}$ in the control flock Estimates of hereditary parameters and watched hereditary patterns affirm that particular reproducing can prompt noteworthy hereditary improvement in Menz sheep.

\section{CONCLUSION}

The consequences of the present investigation demonstrated the low estimates of hereditary improvement in the gainful characteristics recommended that choice was in viable to realize the alluring change. It additionally is shown that the selection of animals couldn't be rehearsed appropriate way and some kind of arbitrary mating had been polished. The hereditary pattern for all presentation attributes demonstrated that the reproducing modified in the present flock during the period under investigation has not demonstrated to be effective. Regard for breed type winds up hurtful when it is engaged without fixing the standard of generation. Along these lines, animals over the normal in genuine value were disposed of in light of the fact that they didn't affirm to breed type in issues which were of almost no monetary significance The hereditary distinction among the individuales is another factor which decides the rate of hereditary improvement that can be cultivated through determination. With a low estimate of heritability, the foreseen improvement in the qualities referenced in the present examination clearly ecological changes achieves more than choice as looked at in the population. This low estimates of hereditary contrasts among the people was considered as a significant factor that rendered determination insufficient It is presented that in the farming of flock population and practices once in a while low live weight winnowing premise was polished. The prescribed dimension of separating in the flock must be pursued and discarded the animals which are unfit for reproducing, for example, sick and repeaters.The present investigation appeared and inferred that these components assume a key job in the improvement of the execution of the animals, while choice stayed insufficient to achieve the ideal changes in the course of the most recent 17 years time frame. It proposed that better nourishing, the board and determination will improve the circumstance.

\section{Implications}

The primary driver of hereditary non improvement in repreductive qualities in ebb tide and flow study could be identified with elements, for example, absence of rearing destinations, non-utilizing of proper determination criteria and accentuation on that over the various years and furthermore ecological and overseeing changes. Additionally, exclusive requirement blunder and serious variances of rearing worth mean are the reasons for being irrelevant of hereditary pattern for reproductive characteristics. It appears that there was no particular rearing project and right choice criteria in order to improve hereditarily qualities on the advantages of Kajli sheep as of late. Subsequently, performing more audit of rearing ones for this sheep appeared to be important.

\section{Competing Interest Statement}

Authors declare that there is no conflict of interest.

\section{REFERENCES}

1. Khan B. The role of livestock in the National economy. Animal Husbandry, National Book Foundation; 1994:1-9.

2. Tariq Mskmm, Bajwa Awma, Kakar Maama, Marghazani Fabib, Shafee Nrthm, Javed Y. Evaluation of Economic Traits of Balochi and Bibrik (Beverigh) Sheep Breeds of Balochistan, Pakistan.

3. Eyduran E, Karakus K, Karakus S, Cengiz F. Usage of factor scores for determining relationships among body weight and some body measurements. Bulgarian Journal of Agricultural Science. 2009;15(4):374-8.

4. Qureshi M, Ghaffar A, editors. Performance of Kajli sheep in Pakistan. 2. Influence of environment on reproduction traits. Proc 7th World Congress on Genetics Applied to Livestock Improvement; 2002.

5. Parihar K. Studies of genetic and phenotypic trends of growth and wool traits in magra SHEEP: Rajasthan University Veterinary and Animal Sciences, Bikaner-334001; 2012.

6. Patterson HD, Thompson R. Recovery of interblock information when block sizes are unequal. Biometrika. 1971;58(3):545-54.

7. Henderson CR. Sire evaluation and genetic trends. Journal of Animal Science. 1973;1973(Symposium):10-41.

8. Babar ME. Genetics and phenotypic parameters of some performance characteristics of lohi sheep: University of Agriculture Faisalabad; 1994. 
9. Neser F, Erasmus G, Van Wyk J. Genetic parameter estimates for pre-weaning weight traits in Dorper sheep. Small Ruminant Research. 2001;40(3):197-202.

10. Ali S, Hussain A, Akhtar P, Younas M, Khan M. Relationship of birth weight of lambs with age of ewes at service in Rambouillet sheep. Pakistan Veterinary Journal. 2006;26(4):187.

11. Bahreini Behzadi M, Shahroudi FE, Van Vleck LD. Estimates of genetic parameters for growth traits in Kermani sheep. Journal of Animal Breeding and Genetics. 2007;124(5):296-301.

12. Akhtar P, Ali S, Hussain A, Mirza MA, Mustafa MI, Sultan JI. Heritability Estimates of Post Weaning Performance Traits of Hissardale Sheep in Pakistan. Turkish Journal of Veterinary and Animal Sciences. 2008;32(4):275-9.

13. Qureshi MA, Khan SA, Shafique M, Sabir N, Ahmed G. Influence of genetic and Non-genetic factors on quantity and quality of wool from sheep reared at Rawalakot Azad Jammu and Kashmir. Journal of Animal and Plant Sciences. 2013;23:205.

14. El Fadili M, Michaux C, Detilleux J, Leroy P. Genetic parameters for growth traits of the Moroccan Timahdit breed of sheep. Small ruminant research. 2000;37(3):203-8.

15. Hanford KJ, Van Vleck LD, Snowder G. Estimates of genetic parameters and genetic trend for reproduction, weight, and wool characteristics of Polypay sheep. Livestock Science. 2006;102(12):72-82.

16. Miraei-Ashtiani SR, Seyedalian SAR, Shahrbabak MM. Variance components and heritabilities for body weight traits in Sangsari sheep, using univariate and multivariate animal models. Small Ruminant Research. 2007;73(1-3):109-14.

17. Vatankhah M, Talebi M. Heritability estimates and correlations between production and reproductive traits in Lori-Bakhtiari sheep in Iran. South African Journal of Animal Science. 2008;38(2):110-8.

18. Akhtar Qureshi M. Genetics and environmental components of variation in performance traits of kajlisheep in pakistan: University of Agriculture Faisalabad Pakistan; 1996.

19. Borg RC. Phenotypic and genetic evaluation of fitness characteristics in sheep under a range environment: Virginia Tech; 2007.

20. Borghese A, Mazzi M. Buffalo population and strategies in the world. Buffalo production and research. 2005;67:1-39.
21. Lewer R, Woolaston R, Howe R. Studies on Western Australian Merino Sheep. II. Genetic and phenotypic parameter estimates for objectively measured traits on ram and ewe hoggets using different model types. Australian Journal of Agricultural Research. 1994;45(4):829-40.

22. Tariq M, Bajwa M, Waheed A, Eyduran E, Abbas F, Bokhari F. Growth curve in Mengali sheep breed of Balochistan. The $\mathrm{J}$ Anim and Plant Sci. 2011;21(1):5-7.

23. Mohammadi K, Abdollahi-Arpanahi R, Amraei F, Mohamadi EM, Rashidi A. Genetic parameter estimates for growth and reproductive traits in Lori sheep. Small Ruminant Research. 2015;131:35-42.

24. Hassen Y, Fuerst- Waltl B, Sölkner J. Genetic parameter estimates for birth weight, weaning weight and average daily gain in pure and crossbred sheep in Ethiopia. Journal of Animal Breeding and Genetics. 2003;120(1):29-38.

25. Tariq MM, Bajwa MA, Abbas F, Waheed A, Bokhari FA, Rafiq M. Heritability of pre-weaning growth performance traits in Mengali sheep in (Balochistan) Pakistan. International Journal of Biodiversity and Conservation. 2010;2(10):284-8.

26. Kamali A, Mirzaee H, Naeemipour H, Delghandi A, Farhangfar H, editors. Genetic parameters for growth traits and their relationships with yearling wool weight in Baluchi sheep breed of Iran. Journal of dairy science; 2007: amer dairy science assoc 1111 n dunlap ave, savoy, il 61874 usa.

27. Akhtar M, Javed K, Abdullah M. Single trait analysis for preweaning growth traits of Buchi sheep In Pakistan. Journal of Animal \& Plant Sciences. 2014;24(3):693-9.

28. Hill WG, Edwards M, Ahmed M-K, Thompson R. Heritability of milk yield and composition at different levels and variability of production. Animal Science. 1983;36(1):59-68.

29. Christensen L, Madsen P, Petersen J, editors. The influence of incorrect sire identification on the estimates of genetic parameters and breeding values. Proc 2nd World Congr Genet Appl Livest Prod, Madrid, Spain; 1982.

30. Sorensen D, Kennedy B. Estimation of genetic variances from unselected and selected populations. Journal of Animal Science. 1984;59(5):1213-23.

31. Bosso N, Cisse M, Van der Waaij E, Fall A, Van Arendonk J. Genetic and phenotypic parameters of body weight in West African Dwarf goat and Djallonke sheep. Small Ruminant Research. 2007;67(2-3):271-8. 